\title{
PORTFOLIO CONCENTRATION OF INSTITUTIONAL INVESTORS AND CORPORATE FRAUD
}

\author{
Liyan Zhang \\ Fujian Agriculture and Forestry University, School of Economics and Management \\ DOI: 10.46609/IJSSER.2021.v06i05.012 URL: https://doi.org/10.46609/IJSSER.2021.v06i05.012
}

\begin{abstract}
According to portfolio concentration, this paper divides institutional investors into diversified and investors, and analyse the impact of different types of institutional investors on the corporate fraud of listed companies. Based on the data of China's A-share stock market, the empirical results show that diversified institutional investors increase the number of corporate frauds, while concentrated institutional investors reduce the number of corporate frauds. And in the listed companies with weak internal governance, institutional investors have a greater impact on corporate fraud. In addition, the impact of institutional investors on corporate fraud is affected by the market environment. In the period of non-financial extreme events, the two types of institutional investors have a greater impact on the corporate fraud.
\end{abstract}

Keywords: Institutional investor, Portfolio concentration, Corporate fraud

\section{Introduction}

In recent years, the news about fraud of listed companies often appears in various news media. These corporate frauds will damage the confidence of investors, reduce the long-term value of enterprises, and increase the instability of financial markets. Stock exchanges in various countries have invested a lot of time and energy to curb market manipulation. And academic researchers have invested a lot of attention explore how to curb the occurrence of fraud in listed companies. It is generally believed that CEO, external directors, volatile shareholder meetings and other internal governance structures and external supervision mechanisms can affect the occurrence of fraud in listed companies (Khanna et al., 2015; Chen et al., 2006; Gam et al., 2021; Karpoff and Lou, 2010).

To curb corporate fraud requires not only the efforts of regulators, but also the supervision of market participants. Compared with individual investors, institutional investors have a professional analysis team and shoulder the social expectation of curbing market violations. According to the existing market literature, institutional investors can supervise the management 


\section{International Journal of Social Science and Economic Research}

Volume:06, Issue:05 "May 2021"

of listed companies and improve the level of internal governance (Chen et al., 2006; Ward et al., 2018). However, institutional investors show strong heterogeneity, and their influence on the management of listed companies depends on their own characteristics (Kim et al., 2020; Van Nieuwerburgh and Veldkamp, 2010). In a series of literatures, portfolio concentration has received a lot of attention from researchers. The impact of institutional investors with different portfolio concentration on the management of listed companies is not consistent.

Following Kim et al. (2020), we construct a simple way investor classification based on portfolio concentration, and we examine the impact of centralized and diversified institutions on listed companies' frauds. Previous studies have shown that in enterprises with poor internal governance, management is more likely to conceal bad information(Callen and Fang, 2017; Kim et al., 2011; Ni et al., 2020). We also test the influence of institutional investors on corporate fraud under different levels of internal governance. In addition, during the period of extreme financial events, listed companies and institutional investors face more severe capital pressure, and they show different behavior patterns. Therefore, this paper further examines the differences in the impact of different types of institutional investors on listed companies' frauds during financial extreme events and non-financial extreme events.

The empirical results show that diversified institutional investors increase the number of corporate frauds, while concentrated institutional investors reduce the number of corporate frauds. And in the listed companies with weak internal governance, institutional investors have a greater impact on corporate fraud. Furthermore, the grouping test results in different market environments show that this effect of institutional investors are more significant on the nonextreme financial event period. The conclusion of this paper is helpful to understand the difference of the impact of different types of institutional investors on corporate governance, and also helps the management to formulate policies to combat corporate frauds.

\section{Sample and Variable Construction}

\subsection{Data Source}

To construct the main sample, we begin by obtaining all Chinese companies listed on the China's A-share stock market from 2006 to 2018. The reason why it ends in 2018 is that the inspection of corporate frauds takes a certain period of time. For example, Khanna et al. (2015) found that it takes an average of 2-3 years from the occurrence of corporate frauds to being investigated. And the following samples are excluded: (1) financial companies; (2) companies with delisting risk warning in the sample interval; (3) companies with missing variables. After screening, our final sample consists of 27,979 firm-year observations over the 13-year sample period. Annual 
International Journal of Social Science and Economic Research

ISSN: $2455-8834$

Volume:06, Issue:05 "May 2021"

institutional ownership data, fraud-related data, and accounting information are collected from the China Stock Market and Accounting Research Databases (CSMAR).

\subsection{Variables}

Following Kim et al. (2020), we divide institutional investors into two sub-groups: high and low portfolio concentration. At the end of the year $t$, the investor portfolio concentration of institutional investor $i$ is measured by Herfindahl-Hirschman Index (HHI).

$$
H H I_{i, t}=\sum_{s=1}^{s_{i}}\left(\frac{N_{i, s, t} * P_{s, t}}{\sum_{s=1}^{s_{i}} N_{i, s, t} * P_{s, t}}\right)^{2}
$$

When the Herfinda hl-Hirschman Index $(H H I)$ is higher than the sample median, it is divided into high concentration sub-groups, otherwise it is divided into low concentration sub-groups. At the firm level, the percentage ownership of each investor group is calculated as the number of shares held by each investor group divided by the total number of shares outstanding, denoted by $I O \mathrm{Con}_{s, t}$ and $I O D i v_{s, t}$ for concentrated and diversified institutions, respectively.

There are several types of fraud, including embezzlement, breach of trust, internal transactions, collusion, unfair trade, tax evasion, accounting, and disclosure. In this paper, the number of frauds of listed companies (NumFraud) investigated by China Securities Regulatory Commission in that year is taken as the proxy index to measure corporate fraud.

In addition, following Khanna et al. (2015), we select control variables, including firm size $(M v)$, stock return (Ret), the percentage of management shareholding (Manho), state-owned enterprise(DumState), the percentage of independent directors (IndDirRat), ownership concentration (OCon10), big four auditours (DumBig4) and analyst coverage (Follow).

\section{Empirical Results}

\subsection{Descriptive statistics}

The descriptive statistics of the main variables in this paper are given in Table 1. Column (1) is the variable name, and columns (2) - (9) are the number of observations, mean, standard deviation, minimum, and maximum respectively. The statistical results show that the average shareholding ratio of diversified institutional investors is $15.66 \%$, and that of concentrated institutional investors is $25.87 \%$. This shows that in China's stock market, compared with diversified institutional investors, concentrated institutional investors hold a higher proportion of shares. 
International Journal of Social Science and Economic Research

ISSN: 2455-8834

Volume:06, Issue:05 "May 2021"

Table 1. The caption must be followed by the table

\begin{tabular}{llllll}
\hline stats & $\mathrm{N}$ & mean & $\mathrm{sd}$ & $\mathrm{min}$ & $\max$ \\
\hline IoDiv & 27,979 & 15.66 & 17.08 & 0.00 & 68.73 \\
IoCon & 27,979 & 25.87 & 19.14 & 0.00 & 70.32 \\
NumFraud & 27,979 & 0.28 & 4.35 & 0.00 & 386.00 \\
Mv & 27,979 & 21.94 & 1.47 & 10.84 & 30.89 \\
Ret & 27,979 & 0.25 & 0.86 & -0.88 & 21.53 \\
Manho & 27,979 & 0.10 & 0.18 & 0.00 & 0.90 \\
DumState & 27,979 & 0.44 & 0.50 & 0.00 & 1.00 \\
IndDiRat & 27,979 & 0.37 & 0.05 & 0.00 & 0.80 \\
OCon10 & 27,979 & 57.02 & 15.51 & 21.62 & 90.60 \\
DumBig4 & 27,979 & 0.06 & 0.25 & 0.00 & 1.00 \\
Follow & 27,979 & 7.08 & 9.47 & 0.00 & 80.00 \\
\hline
\end{tabular}

\subsection{The impact of Portfolio concentration on Corporate fraud}

There are different views on institutional investors in financial market literature. On the one hand, institutional investors hold a large number of shares, so they have the incentive to collect information and conduct supervision and management to ensure that the company's investment strategy is consistent with the goal of maximizing long-term value (Klein and $\mathrm{Zu}, 2009$; Helwege et al., 2012). On the other hand, in order to reduce risk and maintain liquidity, many institutional investors' investment strategy is to invest in a large number of different stocks. Under such an investment strategy, institutional investors tend to pursue short-term returns rather than act as supervisors (Bushee, 2001; Manconi et al., 2012). However, institutional investors show great heterogeneity, the impact of their trading behavior on listed companies depends on their respective characteristics, especially the concentration of their portfolios (Cremers and Petajisto, 2009; Van Nieuwerburgh and Veldkamp, 2010). Therefore, we expect that different types of institutional investors have different effects on the fraud of listed companies.

In order to more intuitively observe the relationship between portfolio concentration and corporate fraud, we begin by plotting the corporate fraud measure (NumFraud) against institutional ownership. First, we divide the entire sample into 5 groups by institutional ownership (IODIV and IOCon). We then calculate the mean values of corporate frauds foreach group. Finally, we plot the mean values against groups from lowestto highest. The results of Figure 1 show that the number of corporate frauds increases with the increase of the proportion of diversified institutional ownership. With the decrease of the concentrated institutional ownership, the number of corporate frauds gradually decreases. For both institutional investors, 
the difference between the first group and the fifth group is 0.60 and -0.41 respectively, and the difference is statistically significant.

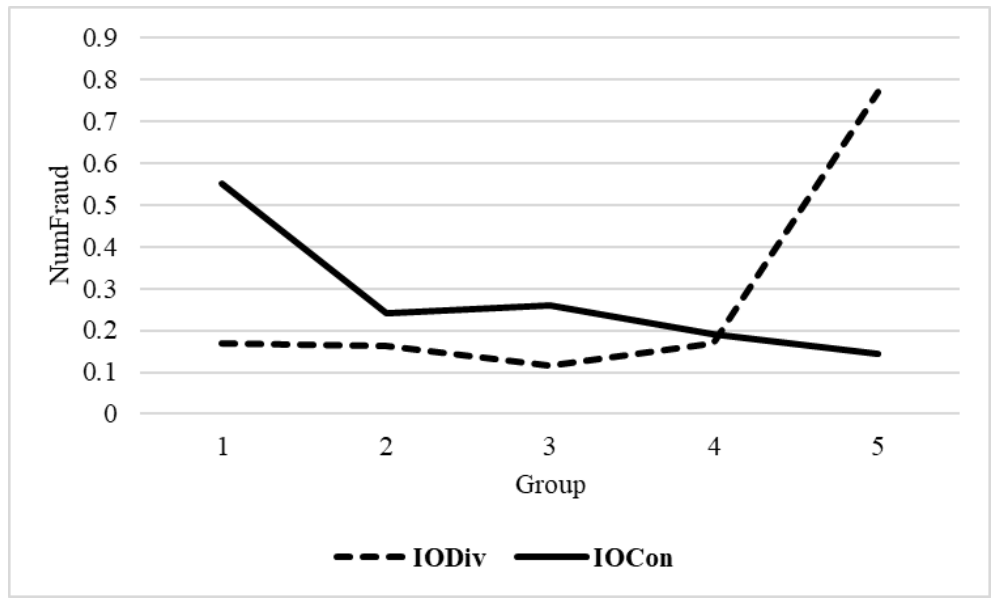

Fig. 1.Univariate analysis

More formally, in order to test this result, this paper uses models (2) and (3) to estimate the impact of diversified institutional investors and concentrated institutional investors on the corporate fraud of listed companies.

$$
\begin{aligned}
& \text { NumFraud }_{s, t+1}=\beta_{0}+\beta_{1} * \text { IoDiv }_{s, t}+\beta_{2} * \text { Control }_{s, t}+\text { YearFe }+ \text { IndustryFe } \\
& \text { NumFraud }_{s, t+1}=\beta_{0}+\beta_{1} * \text { IoCon }_{s, t}+\beta_{2} * \text { Control }_{s, t}+\text { YearFe }+ \text { IndustryFe }
\end{aligned}
$$

Where NumFraud N $t+1_{1}$ is the number of corporate frauds of list company $s$ in $t+1$ year.IoDiv $v_{s, t}$ andIoCon,$t$ are diversified institutional ownership and concentrated institutional ownership of list company $s$ in $t$ year respectively. Control ${ }_{s, t}$ is control variables. YearFeand IndustryFeare year fixed effect and industry fixed effect respectively. The results of the above estimations are shown in Table 2. Columns (1) and (3) introduce the diversified institutional ownership and concentrated institutional ownership, and control the year fixed effect and industry fixed effect. Columns (2) and (4) further add control variables.

The estimation results in columns (1) - (2) show that at the significance level of $1 \%$, the coefficient of IODIv is significantly positive, that is, the greater the diversified institutional ownership, the greater the number of corporate frauds of listed companies. On average, every $1 \%$ increase in the diversified institutional ownership will increase the number of corporate frauds by $0.007 \%$. The estimation results in columns (3) - (4) show that at the significance level of $1 \%$, the coefficient of IOCon is significantly negative, that is, the greater the concentrated institutional ownership, the lower the number of corporate frauds of listed companies. On average, every $1 \%$ increase in the concentrated institutional ownership will reduce the number of corporate frauds 
by $0.009 \%$. The above estimation results show that the diversified institution is short-term investors and do not play a supervisory role to the management. And the concentrated institution act as the role of supervisors, reducing the number of corporate frauds.

Table 2.The impact of Portfolio concentration on Corporate fraud

\begin{tabular}{lllll}
\hline & $(1)$ & $(2)$ & $(3)$ & $(4)$ \\
VARIABLES & NumFraud & NumFraud & NumFraud & NumFraud \\
\hline IoDiv & $0.007^{* * *}$ & $0.008^{* * *}$ & & \\
& $(4.67)$ & $(4.75)$ & & $-0.009^{* * *}$ \\
IoCon & & & $-0.003^{* * *}$ & $(-5.97)$ \\
& & & $(-2.64)$ & YES \\
Control FE & NO & YES & NO & 27,979 \\
Observations & 27,979 & 27,979 & 27,979 & 0.164 \\
R-squared & 0.157 & 0.163 & 0.156 & \\
\hline
\end{tabular}
Note: $*, * *, * * *$ denotes $10 \%, 5 \%$, and $1 \%$ levels of statistical significance, respectively.

\subsection{Internal corporate governance}

Next, we conduct several cross-sectional tests to test whether the influence of different types of institutional investors on corporate fraud is affected by the level of internal governance. Previous studies have shown that in enterprises with poor internal governance, management is more likely to conceal bad information(Callen and Fang, 2017; Kim et al., 2011; Ni et al., 2020). Therefore, we speculate that in the listed companies with low level of internal governance, institutional investors will have a greater impact on corporate fraud.

We examine the above prediction using two proxies for internal corporate governance. Our first proxy of internal corporate governance is the CEO duality. CEOs who are also the chairpersons of the board can significantly influence corporate governance. Prior studies suggest that these dual CEOs are more likely to withhold bad news(Gul and Leung, 2004; Ni et al., 2020). The grouping test results are listed in Table 3 panel A. The estimation results in Panel A show that the effect of different types of institutional investors is significantly stronger for firms with CEO duality. On average, every $1 \%$ increase in the diversified institutional ownership will increase the number of corporate frauds by $0.011 \%$,every $1 \%$ increase in the concentrated institutional ownership will reduce the number of corporate frauds by $0.014 \%$.

Table 3. Internal corporate governance

\begin{tabular}{lllll}
\hline Panel A: CEO duality & & & & \\
& $(1)$ & $(2)$ & $(3)$ & $(4)$ \\
& Low & & High & \\
VARIABLES & L1NumFraud & L1NumFraud & L1NumFraud & L1NumFraud \\
\hline \hline www.ijsser.org & \multicolumn{2}{c}{ Copyright C IJSSER 2021, All rights reserved } & Page 1531
\end{tabular}


International Journal of Social Science and Economic Research

ISSN: 2455-8834

Volume:06, Issue:05 "May 2021"

\begin{tabular}{lllll} 
IoDiv & 0.002 & & $0.011^{* * *}$ & \\
& $(0.36)$ & & $(4.01)$ & $-0.014^{* * *}$ \\
IoCon & & 0.000 & & $(-5.13)$ \\
& & $(0.00)$ & YES \\
Year FE & YES & YES & YES & 21,534 \\
Observations & 6,445 & 6,445 & 21,534 & 0.345 \\
R-squared & 0.695 & 0.695 & 0.345 & $(4)$ \\
\hline Panel B: G-index & & & & \\
\hline & $(1)$ & $(2)$ & $(3)$ & L1NumFraud \\
VARIABLES & Low & & High & \\
\hline IoDiv & L1NumFraud & L1NumFraud & L1NumFraud & $-0.015^{* * *}$ \\
& 0.005 & & $0.010^{* * *}$ & $(-3.83)$ \\
IoCon & $(1.34)$ & & $(2.73)$ & YES \\
& & -0.004 & & 12,337 \\
Year FE & & $(-1.07)$ & & 0.275 \\
Observations & YES & YES & YES & 12,337 \\
R-squared & 15,642 & 15,642 & 0.275 & \\
\hline
\end{tabular}

Note: $*, * *, * * *$ denotes $10 \%, 5 \%$, and $1 \%$ levels of statistical significance, respectively.

Our second proxy of internal corporate governance is G-Index (Gompers et al., 2003). A higher G-Index represents a deep-rooted manager with a lower level of internal governance. According to whether the G-Index is higher than the sample median, this paper divides the sample into low G-Index sub sample and high G-Index sub sample, and tests the influence of different institutional investors on corporate fraud. The grouping test results are listed in Table 3 panel B. The results show that the effect of centralized and diversified institutional investors on corporate fraud is stronger in the high G-Index sub samples. On average, every $1 \%$ increase in the diversified institutional ownership will increase the number of corporate frauds by $0.010 \%$,every $1 \%$ increase in the concentrated institutional ownership will reduce the number of corporate frauds by $0.015 \%$. But in the low G-Index sub samples, the above effects are not significant.

Generally speaking, the evidence from the cross-section analysis above shows that institutional investors have more influence on corporate fraud in listed companies with weak internal governance level. This finding is consistent with that of $\mathrm{Ni}$ et al. (2020).

\subsection{Extreme Financial Event}

In the sample range of this paper, China's stock market experienced two extreme financial events: "2008 financial crisis" and "2015 stock disaster". During the outbreak of extreme financial events, the stock market fluctuates violently, and the financing cost of listed companies rise sharply. Bond financing has become an important source of external financing for listed companies. Manconi et al. (2012) found that during the financial crisis, financial institutions 
were the main investors of bonds, and commercial banks did not hold bonds for liquidity reasons. Therefore, this paper expects that in the period of extreme financial event, for the sake of investment income, institutional investors will more actively intervene in the management decision-making of management, and have less impact on fraud. In order to test this hypothesis, this paper divides the sample into two sub samples during the extreme financial event and nonextreme financial event, and examines the differences of the impact of different types of institutional investors on corporate fraud in different market environments.

Table 4 reports the impact of different types of institutional investors on corporate fraud in different sub samples. The empirical results show that during the non-extreme financial event period, on average, the number of corporate frauds increases by $0.036 \%$ for every $1 \%$ increase in the diversified institutional ownership. The number of corporate frauds in listed companies decreased by $0.041 \%$ for every $1 \%$ increase in the concentrated institutional ownership. During the extreme financial event period, the impact was $0.008 \%$ and $-0.009 \%$ respectively. The empirical results show that in the period of extreme financial event, diversified institutional investors and concentrated institutional investors have less impact on corporate fraud.

Table 4. Extreme financial event

\begin{tabular}{lllll}
\hline & $(1)$ & $(2)$ & $(3)$ & $(4)$ \\
VARIABLES & NumFraud & NumFraud & NumFraud & NumFraud \\
\hline IoDiv & $0.036^{* * *}$ & & $0.008^{* * * *}$ & \\
& $(3.76)$ & & $(4.75)$ & $-0.009^{* * *}$ \\
IoCon & & $-0.041^{* * *}$ & & $(-5.97)$ \\
& & $(-4.57)$ & & YES \\
Control FE & YES & YES & YES & 27,979 \\
Observations & 3,982 & 3,982 & 27,979 & 0.164 \\
R-squared & 0.284 & 0.285 & 0.163 & \\
\hline
\end{tabular}

Note: $*, * *, * * *$ denotes $10 \%, 5 \%$, and $1 \%$ levels of statistical significance, respectively.

\section{Robustness Test}

In order to enhance the robustness of the research conclusions, the following robustness tests were carried out.

First, two stage least squares (TSLS). Different types of institutional investors have different preferences for listed companies. This paper is faced with potential endogenous problems. In order to reduce the impact of potential endogeneity, this paper takes the average shareholding ratio of the same type of institutional investors in the same industry in the same year as an instrumental variable, and uses two-stage least squares estimation to further test the robustness of 
the conclusion. The estimated results are listed in columns (1) - (2) of Table 5.The results of the two-stage least squares are the same as above mentioned.

Second, Firm fixed-effects regressions. The relationship between different types of institutional investors and fraud behavior of listed companies may also be affected by other unobservable company characteristics, which may also cause endogenous problems. Hence, we implement firm fixed-effect regressions for Eq. (2) and (3) to address the concern that omitted timeinvariant firm characteristics may be driving the results. The estimated results are listed in columns (3) - (4) of Table 5.The findings are in line with the primary results, and further confirm the robustness of our results.

Third, Regressions for longer-run windows. We further analyze the impact of different types of institutional investors on corporate frauds in the next two years. The estimated results are listed in columns (5) - (6) of Table 5. The empirical results are basically consistent with the above.

Table 5.Robustness test

\begin{tabular}{|c|c|c|c|c|c|c|}
\hline \multirow[b]{3}{*}{ VARIABLES } & (1) & (2) & (3) & (4) & (5) & (6) \\
\hline & \multicolumn{2}{|l|}{ TSLS } & \multicolumn{2}{|l|}{ Firm Fe } & \multicolumn{2}{|c|}{ Longer-run windows } \\
\hline & NumFraud & NumFraud & NumFraud & NumFraud & NumFraud & NumFraud \\
\hline IoDiv & $\begin{array}{l}0.037 * * * * \\
(4.43)\end{array}$ & & $\begin{array}{l}0.010^{* * * *} \\
(3.75)\end{array}$ & & $\begin{array}{l}0.007 * * \\
(2.26)\end{array}$ & \\
\hline IoCon & & $\begin{array}{l}-0.035^{* * *} \\
(-4.42)\end{array}$ & & $\begin{array}{l}-0.011 * * * \\
(-4.50)\end{array}$ & & $\begin{array}{l}-0.003 * * \\
(2.33)\end{array}$ \\
\hline Control & YES & YES & YES & YES & YES & YES \\
\hline Observations & 27,979 & 27,979 & 27,533 & 27,533 & 24,580 & 24,580 \\
\hline R-squared & 0.163 & 0.163 & 0.363 & 0.363 & 0.106 & 0.150 \\
\hline
\end{tabular}

Note: $* * *, * * *$ denotes $10 \%, 5 \%$, and $1 \%$ levels of statistical significance, respectively.

\section{Conclusion}

According to portfolio concentration, this paper divides institutional investors into diversified and investors, and analyse the impact of different types of institutional investors on the corporate fraud of listed companies. Based on the data of Listed Companies in China's A-share stock market from 2006 to 2018, this paper empirically tests the relationship between portfolio concentration of institutional investors and corporate frauds. The empirical results show that diversified institutional investors increase the number of corporate frauds, while concentrated institutional investors reduce the number of corporate frauds. And in the listed companies with weak internal governance, institutional investors have a greater impact on corporate fraud. Further, this paper examines the impact of institutional investors on the corporate frauds under different market conditions. The results show that in the extreme financial time, institutional 


\section{International Journal of Social Science and Economic Research}

ISSN: $2455-8834$

Volume:06, Issue:05 "May 2021"

investors have less impact on corporate frauds. Therefore, our research conclusion will help to restrain the illegal behavior of corporate and improve market governance.

\section{References}

[1] Bushee B J,"Do institutional investors prefer near-term earnings over long-run value?"Contemporary Accounting Research, 2001, vol.18, no.2, pp.207-246, 2001.

[2] Callen J L and Fang X,"Crash risk and the auditor-client relationship," Contemporary Accounting Research, vol.34, no.3, pp.1715-1750, 2017.

[3] Chen G, Firth M, Gao D N, et al, “Ownership structure, corporate governance, and fraud: Evidence from China,’Journal of Corporate Finance, vol.12, no.3, pp. 424-448., 2006.

[4] Cremers K J M and Petajisto A, "How active is your fund manager? A new measure that predicts performance," The review of financial studies, vol.22, no.9, pp.3329-3365, 2009.

[5] Gam Y K, Gupta P, Im J, et al,"Evasive shareholder meetings and corporate fraud,”Journal of Corporate Finance, vol.66, pp.101807, 2021.

[6] Gompers P, Ishii J, Metrick A, “Corporate governance and equity prices,” The quarterly journal of economics, vol.118, no.1, pp.107-156, 2003.

[7] Gul F A and Leung S, "Board leadership, outside directors' expertise and voluntary corporate disclosures," Journal of Accounting and public Policy, vol.23, no.5, pp.351-379, 2004.

[8] Helwege J, Intintoli V J, Zhang A,"Voting with their feet or activism? Institutional investors' impact on CEO turnover,"Journal of Corporate Finance, nol.18, no.1, pp.22-37, 2012.

[9] Karpoff J Madn Lou X, "Short sellers and financial misconduct," The Journal of Finance, vol.65, no.5, pp.1879-1913, 2010.

[10] Khanna V, Kim E H, Lu Y,“CEO connectedness and corporate fraud," The Journal of Finance, vol.70, no.3, pp.1203-1252, 2015.

[11] Kim J B, Li Y, Zhang L, "Corporate tax avoidance and stock price crash risk: Firm-level analysis," Journal of Financial Economics, vol.100, no.3, pp.639-662, 2011.

[12] Kim, Donghan, Hyun Dong Kim, Denis Yongmin Joe, and Ji Yeol Jimmy Oh, "Institutional 
Investor Heterogeneity and Market Price Dynamics: Evidence from Investment Horizon and Portfolio Concentration,” Journal of Financial Markets, pp. 100604, 2000.

[13] Klein A andZur E,"Entrepreneurial shareholder activism: Hedge funds and other private investors," The Journal of Finance, vol.64, no.1, pp.187-229, 2009.

[14] Manconi A, Massa M, Yasuda A, "The role of institutional investors in propagating the crisis of 2007-2008," Journal of Financial Economics, vol.104, no.3, pp.491-518, 2012.

[15] Ni X, Peng Q, Yin S, et al.,"Attention! Distracted institutional investors and stock price crash," Journal of Corporate Finance, vol.64, pp.101701, 2020.

[16] Van Nieuwerburgh S and Veldkamp L,"Information acquisition and under-diversification," The Review of Economic Studies, vol.77, no.2, pp.779-805, 2010.

[17] Ward C, Yin C, Zeng Y,"Institutional investor monitoring motivation and the marginal value of cash," Journal of Corporate finance, vol.48, pp.49-75, 2018. 